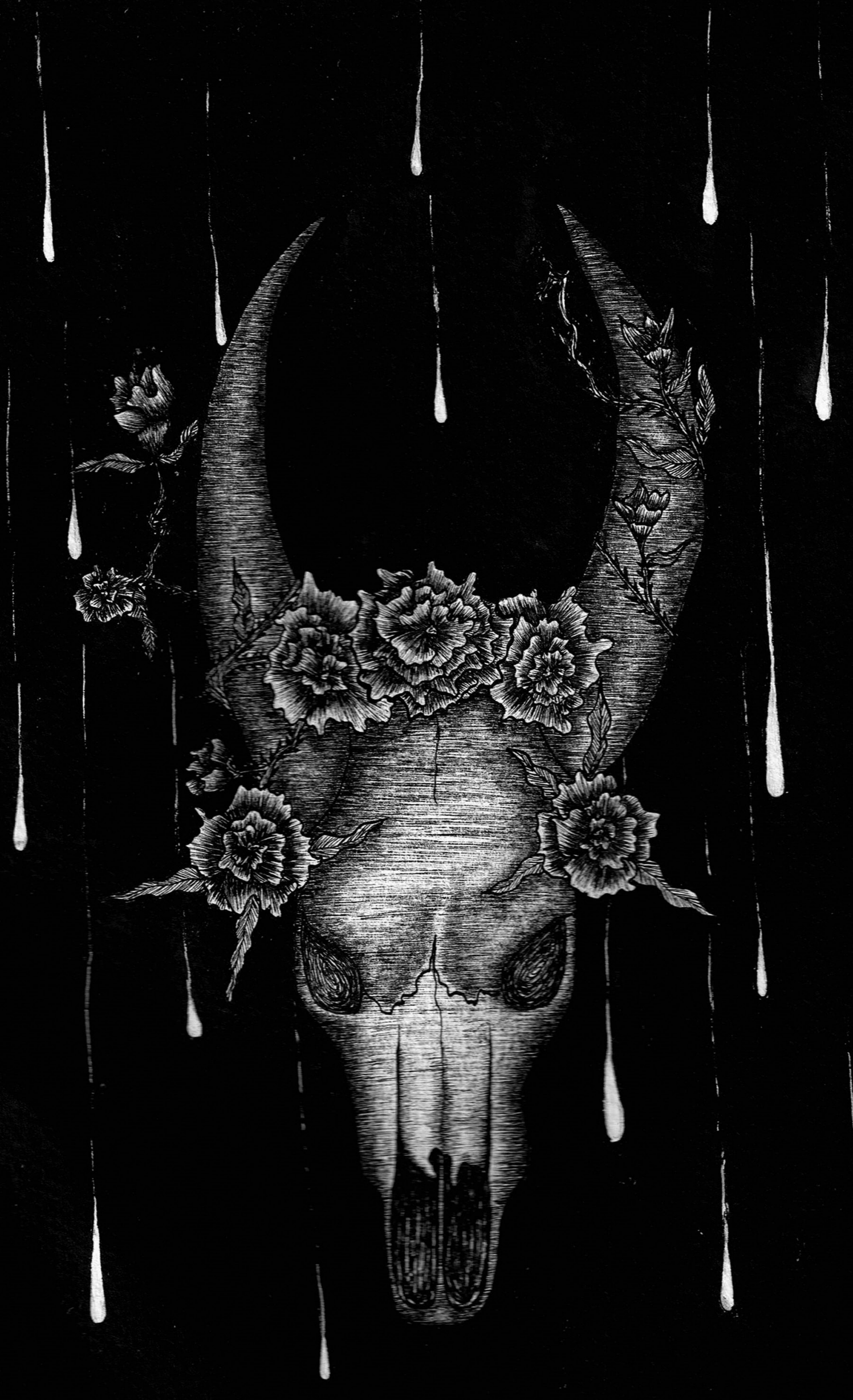

Capricorn (2019). Tinta china sobre papel de algodón: Larvae (Anel Martínez). Prohibida su reproducción en obras derivadas. 


\section{La conformación de la subjetividad a través de la mirada ideológica}

THE SHAPING OF SUBJECTIVITY THROUGH AN IDEOLOGICAL LOOK

Sergio José Aguilar-Alcalá*

* Universidad Autónoma de Yucatán,

México

Correo-e: sergio.aguilaralcala@

gmail.com

Recibido: 26 de agosto de 2018

Aprobado: 21 de enero de 2019

Resumen: A partir de los conceptos de 'mirada vigilante' — expuesto por Foucault y Mathiesen—y 'otredad' — planteado por Lacan y Žižek—, se hace una reflexión sobre el sujeto como el punto de falla del edificio ideológico en la democracia liberal contemporánea. Mediante la vista de paralaje y el reconocimiento de la lucha de clases (como núcleo Real de la democracia liberal), se plantea la posibilidad de superar la discusión sobre lo Particular del individuo — dado por la raza, el género, la etnia- a fin de construir una posición de enunciación que nos permita señalar un carácter Universal.

Palabras clave: filosofía; psicoanálisis; política; economía; ideología; sociedad contemporánea

Abstract: From the concepts of 'vigilant look' —exposed by Foucault and Mathiesen — and 'otherness' — proposed by Lacan and Žižek —, a reflection is made on the subject as the failure point of the ideological building in contemporary liberal democracy. By means of parallax and the recognition of class struggle (as the actual core of liberal democracy), we propose the possibility of overcoming the discussion on the particular of the individual — given by race, gender, ethnicity — so as to build an enunciation position that allows us to point at a universal character.

Keywords: philosophy; psychoanalysis; politics; economics; ideologies; contemporary society 


\section{INTRODUCCIÓN}

En las democracias liberales contemporáneas se escucha con frecuencia sobre la necesidad de reconocer las identidades particulares y sus modos de alcanzar sus metas. Asimismo, son comunes ideas como que 'se puede trabajar más allá de las diferencias', 'es posible tolerar todo menos la intolerancia' y 'se puede convivir, aunque estemos en desacuerdo'. Este reconocimiento de las identidades particulares y la posibilidad de que alcancen su propio bienestar en una situación de equidad para todas y cada una es lo que buscan las luchas de las minorías, ya sea sexuales, étnicas, raciales, etcétera. Constituye también el ideal implícito en la democracia participativa, donde diferentes grupos luchan por mediar agendas y metas.

Aquí es donde se halla, sin embargo, un impasse específico de la democracia, una lucha que se enuncia como universal: la lucha de clases. La ofuscación de su universalidad cumple el sueño de la economía del libre mercado, asentada en una concepción individual del agente económico. Precisamente, cuando el modelo político-económico está en busca de un lugar para que cada quien se desarrolle en libertad, viene bien la reflexión sobre el sujeto mismo.

La discusión sobre el nacimiento del sujeto ha encontrado posturas contrarias: desde la noción de interpelación althusseriana, en la que es el punto de articulación ideológica, a la noción lacaniana de sujeto como vacío que muestra la falta del orden simbólico (y en ese sentido, es el lugar donde falla la articulación ideológica). Se puede ver al sujeto como sometido a la vigilancia panóptica o como el que busca la atención de la mirada sinóptica. También se puede entender como quien es mirado por otro sujeto (Sartre), como quien se sabe mirado por un objeto (Lacan), o como quien cambia su posición para mirar al objeto (Žižek). En cualquiera de estos casos no sólo se intenta responder al problema del nacimiento de la subjetividad, sino que también se resuelve (al menos implícitamente) el asunto de la capacidad de agencia del sujeto.

En este texto se presentan algunas ideas clave para entender la construcción del sujeto. Los conceptos de 'mirada' e 'ideología' constituyen puntos de anclaje para la subjetividad (ya sea para someterse o negarse a ella). La articulación de estas concepciones tiene como objetivo alertar sobre la posibilidad de superar la noción particular del sujeto (por medio de las identidades particulares de raza, sexualidad, etnicidad, etcétera) con el fin de hallar una posición simbólica específica que nos permita enunciar su universalidad. Esta posición es paradójica, pues con ella no se pretende borrar las identidades particulares, sino que mediante el reconocimiento en la posición universal éstas pueden conseguir sus metas. El precio que habrá que pagar es cuestionar el modo en que se enuncia la propia subjetividad.

\section{El ESPECTÁCULO DE LA VIGILANCIA}

En los estudios culturales están bastante difundidas las ideas del clásico publicado en 1975, Vigilar y castigar (2003), de Michel Foucault. El inicio del libro sintetiza la tesis principal: del castigo sobre el cuerpo en la tortura carnavalesca que tenía lugar en la plaza pública, pasamos al castigo sobre el alma en la prisión apartada de la ciudad. Este cambio requería reconocer en los sujetos un exceso a controlar o educar. Iba desde la postura correcta de la mano al escribir a la ridícula rutina de los presos en una cárcel. Todos estos procesos de control sobre los sujetos culminan en un dispositivo disciplinario específico, que se articula en la praxis del panóptico: ${ }^{1}$ una estructura arquitectónica en la que una torre central tiene acceso para ver las diferentes unidades (prisiones, hospitales, escuelas, barracas

1 Esta disposición del espacio fue ideada por Jeremy Bentham en el siglo XVIII. 
militares). La división panóptica supone un aislamiento de los sujetos - al ponerlos en celdas individuales, con tal de evitar el descontrol y agencia de las masas-, y su total visibilización por parte del poder central — todo el tiempo pueden ser vistos por él, pero no pueden verlo-. El panóptico supone, en pocas palabras, una mirada central que observa a todos lados, pero a la que los individuos no pueden corresponder: no saben en qué momento están siendo vistos y en qué momento no.

Con esto, se alcanza una permanente presencia virtual de aquel que controla 'a través' de cada sujeto: como los prisioneros no saben cuándo son vigilados (si hay un guardia viéndoles o si la torre central está vacía), éstos se controlan a sí mismos, voluntariamente, todo el tiempo. En palabras de Foucault, "los detenidos se hallan insertos en una situación de poder de la que ellos mismos son los portadores" (2003: 204).

Así, el panóptico no sólo tiene la función de establecer claras dicotomías (preso/libre, loco/ sano, alumno/maestro), también impone un sentido de autocontrol y vigilancia en quienes están 'sujetados a la mirada': el poder se hace efectivo no sólo cuando actúa 'sobre' los sujetos (cuando éstos ven que son mirados), sino también cuando actúa 'a través de' ellos (cuando siguen la disciplina sin importar que el poder esté 'presente'). El poder funciona gracias a su presencia coactiva y a la fantasmal amenaza potencial.

Si bien la arquitectura panóptica es la que explota esta idea de manera literal, es más interesante cuando Foucault reconoce que la invisibilización de la torre central no supone un espacio más 'libre' del poder, al contrario, representa el éxito del poder para ocultarse. El hecho de que no necesitemos ver su manifestación física implica el triunfo de su instauración.

Escapa a los intereses de este texto una revisión del impacto del panóptico foucaultiano en las ciencias sociales y humanidades, más allá de mencionar su enorme adopción por parte de los estudios culturales. ${ }^{2}$ Es curioso que la sociedad contemporánea esté muy preocupada por ser tan susceptible a la vigilancia desmedida, y al mismo tiempo, sea partícipe voluntaria de la misma. David Lyon (2005: 36) sostiene que la sobrevigilancia es aceptada porque el ecosistema mediático ha banalizado las imágenes y la sociedad de la mirada, donde se rompe la frontera entre lo público y lo privado: ya hay cámaras en espacios públicos, negocios, oficinas gubernamentales, escuelas... ¿ ¿de qué servirá tener una más en mi casa y otra para vigilarme en la calle?

Es aquí donde resulta de gran interés revisar la contraparte no tan conocida del panóptico: el sinóptico. Una de las críticas a la obra de Foucault es su omisión de los medios masivos de comunicación, que jugaron un papel fundamental en el proceso de globalización del siglo pasado - aunque quizá esto se deba a que el filósofo intentaba alejarse de los estructuralistas franceses, como Barthes y Metz, y el interés de éstos por analizar la publicidad y el cine- - Sin embargo, con las teorías de lo digital, es cada vez más obvia la necesidad de estudiar esta noción a la vista de los postulados sobre el control y el poder que Foucault pudo trazar.

El concepto de 'sinóptico' fue propuesto para el estudio del poder por Thomas Mathiesen en su artículo "The viewer society. Michel Foucault's 'Panopticon' revisited” (1997). El autor inicia su argumentación recordando que el panóptico pretendía que el sujeto cayera en la lógica de la autovigilancia, al no saber en qué momentos estaba siendo observado y en cuáles no. Pero mientras el fenómeno donde pocos ven a muchos efectivamente tiene lugar, la sociedad del espectáculo explota la lógica contraria: muchos

2 A pesar de que se ha tratado de escapar del panóptico en los estudios sobre la vigilancia, la multiplicación de términos ha mostrado la importancia básica que supone el modelo de Foucault. 'Post-panóptico', 'panóptico electrónico' y 'pornóptico' son algunos ejemplos que pueden hallarse. 
viendo a pocos, un sinóptico (1997: 218) donde un objeto se vuelve el centro de interés de múltiples miradas.

Mathiesen sostiene que el panóptico y el sinóptico se desarrollaron simultáneamente (1997: 219). El origen del primero se puede rastrear en la arquitectura de prisiones, escuelas y hospitales, el antiguo del sinóptico se puede ver en los desfiles militares y centros de espectáculos. Lejos de tratarse de un desarrollo paralelo, ha habido muchos cruces en actividades e instituciones que combinan ambos sistemas de vigilancia. Por ejemplo, el confesionario católico es un proceso panóptico, pero el arreglo del dispositivo de mirar y escuchar al cura dar misa es sinóptico.

Teniendo en cuenta el año de su artículo, resulta interesante que Mathiesen cuestione la supuesta libertad del internet, así como su naturaleza "pública" o el hecho de que esté "al alcance de todos" (1997: 224). Podría especularse que la brecha digital que el autor menciona es muchísimo menor hoy, pero sigue siendo válido cuestionar de qué sirve esto si el contenido está más controlado y sigue sin producir un cambio de educación en el usuario: si hay una sólida prueba de que a la abundancia de información no le sigue la abundancia de reflexión, ésa es el internet. ${ }^{4}$

Mathiesen señala que la ostentación pública del poder ya no es un proceso tan espectacularizante, sino que se restringe a espacios y lugares específicos (1997: 226). Al igual que el castigo público que Foucault describe al principio de su obra dejó de tener lugar para trasladarlo del cuerpo al alma y de la calle a la prisión, así se trata de borrar cada vez más las huellas del poder en las esferas de la sociedad.

3 Mathiesen usa el prefijo 'sin' ('junto'), ya que no hay sólo un guardia en la torre sino un grupo de sujetos. Otro término que podría usarse es 'oligóptico', de 'oligo' ('pocos'), como en la palabra 'oligarquía'. Para mantenerme fiel al trabajo de Mathiesen, seguiré usando el concepto 'sinóptico'.

4 Con el grave problema del fin de la neutralidad en la red en Estados Unidos y su probable adopción en el resto del mundo, la brecha digital sólo se seguirá expandiendo.
Hoy que los usuarios de redes sociales se dejan llevar fácilmente por la visceralidad (la historia de acoso en la calle, la foto del niño abusado, el perrito muerto, la explicación con caricaturas en tres viñetas de un complejo conflicto de terrorismo, la nota escandalosa que resulta ser falsa o manipulada), es sumamente importante la reflexión de cómo nuestra actitud como rectores de la moral termina constituyendo la subjetividad de los demás, al ser muchos vigilando a cada uno.

La serie Black Mirror (2011) resumió esto en una muy siniestra y poderosa idea. En el capítu1o "White Christmas" (Tibbetts, 2014), un hombre acusado de ser cómplice de un crimen es usado por la policía para extraer la confesión del inconsciente de otro (mediante una especie de manifestación externa del mismo, una especie de exoinconsciente). Le aligeran la pena, pero al precio de bloquearlo para todos. En la diégesis del capítulo, bloquear a alguien significa que, gracias a los implantes oculares que todos poseen, cuando no se tiene la voluntad de interactuar con una persona, simplemente se convierte su figura en una mancha de estática gris, y su voz en una distorsión incomprensible. Para el personaje castigado, su figura ante los demás no sólo se volverá esa mancha de estática y voz distorsionada, sino que no será color gris, como en un bloqueo tradicional, sino roja, para señalar con mayor peso su crimen pasado. ${ }^{5}$

Así, la posición central sinóptica resulta más inestable que en el panóptico. Un caso interesante para comprender esto es el de las celebridades de redes sociales, conocidas como influencers, que abundan en internet. Estos personajes se

5 iAcaso no sentimos una tremenda ansiedad y angustia, en este mundo de lo políticamente correcto, sobre si no dijimos 'esa' palabra con 'ese' tono que 'quizá' podría entenderse mal en 'una' ocasión, y que a partir de ahora será el significante que nos represente en toda interacción futura pues hemos sellado nuestro destino al ser incapaces de borrar la huella digital (esa que nos vuelve una mancha roja), al ser incapaces de satisfacer la mirada juzgadora de todos los demás sobre nosotros? 
constituyen como el centro de interés de la mirada de miles o hasta millones de seguidores, y en ese sentido, las marcas que promueven y las ideas políticas que sutilmente (o en ocasiones, de forma explícita) venden pueden ser adoptadas por el colectivo. Sin embargo, el proceso puede volverse en su contra, cuando atentan contra alguna regla implícita de la dinámica social de las redes sociales y son juzgados con firmeza.

La creación de los influencers resulta paradójica. Mathiesen (1997: 227) señala que los medios crean a sus figuras para autovalidarse. Creemos que los periodistas tienen un compromiso ético porque se presentan como periodistas, pero se presentan como tales porque dicen tener ese compromiso ético. Es decir, las condiciones de enunciación necesitan sus propios enunciados para validarse, y estos enunciados tienen validez gracias a las propias condiciones de enunciación. En una especie de perversa retroacción, uno es un líder de opinión porque se constituyó como tal, hubo un momento en el que uno 'fingió' para luego poder 'ser' en realidad: primero empezó a ser visto por los demás como líder de opinión, y a partir de ese momento, genuinamente se convirtió en uno. ${ }^{6}$

Para quien sigue creyendo que la diversidad racial, sexual y étnica en los medios de comunicación supone una mayor 'democracia' mediática, vale la pena recordarle lo que Mathiesen señalaba hace años: los medios siguen siendo controlados por las mismas élites que, con una clara agenda de explotación económica, abrazan cualquier política que les permita continuar el ritmo del capital (1997: 227).

La película que presenta la idea del sinóptico al paroxismo es The Truman Show (Weir, 1998). Truman, el seriamente despistado protagonista de un reality show, es usado sin saberlo como conejillo de indias por un semidios/director

6 O como escuché en un congreso, en una ponencia sobre la figura de Kim Kardashian: dicha celebridad es famosa porque es Kim Kardashian. En una paradoja que raya en el absurdo, ella es famosa por el hecho de ser famosa. del programa que controla como titiritero todo el espectáculo de este mundo artificial. En una escena muy famosa, la 'novia' de Truman muestra una caja de chocolate en polvo, mientras le enumera todas las bondadosas propiedades del producto: ella le habla a Truman explícitamente, pero, de forma implícita, también le está dando publicidad a los espectadores que ven el programa. Ahí el protagonista dice la famosa frase: ' $i A$ quién le estás hablando?'.

¿Qué significa dicha pregunta para los propósitos de esta discusión? Caemos en la cuenta de que, con la exposición obsesiva en redes sociales, donde busca validación de sus ‘amigos', el usuario está rogando ser vigilado. Sin embargo, el proceso inverso también está presente, un panóptico en el que pocos vigilan a millones de usuarios de redes sociales: compañías que venden y compran nuestra información (las páginas que visitamos, los productos que nos interesan, la música que escuchamos), criminales cibernéticos que buscan que caigamos presos en sus páginas falsas y parches para sacar información de tarjetas de crédito, gobiernos que espían nuestros pasos (con poca dificultad, ya que nosotros indicamos gustosamente con quién, dónde y qué estamos haciendo). Mientras sostenemos una relación sinóptica con otros usuarios en una plataforma 'horizontal', lo hacemos dentro de un marco que posibilita una relación panóptica con el poder, la inteligencia de datos que dirige nuestro destino y nos conoce mejor que nosotros mismos. ${ }^{7}$

Entonces, ¿a quién le habla la novia de Truman? Ciertamente, a él (en tanto su enunciado), pero lo hace como ventrílocuo de los anunciantes del programa para que ellos hablen con los espectadores a través de ella (se revela aquí su

Los pixeles de grabación en aplicaciones móviles son mecanismos con los que se genera un video de nuestra pantalla mientras se usa una aplicación, para reconocer cuáles son los botones que presiona el usuario, el orden en el que lo hace y cuánto tiempo gasta ahí. Son, en todo sentido de la palabra, miradas que nos vigilan y de las que no estamos al tanto. 
posición de enunciación). En este sentido, hay una primera mirada: la de los espectadores hacia El show de Truman. Pero también una segunda, la de ese objeto que devuelve ocultamente la mirada: el programa de televisión nos ve cuando lo miramos, así nos estudia y cambia su presentación (sólo hace falta recordar que se incluyen y eliminan personajes, se complican y resuelven situaciones, en función del índice de audiencia y los anunciantes).

Gracias a estos dos modelos entendemos la constitución del sujeto como sometido al dispositivo del poder que lo mira (panóptico) o como agente que constituye a otros sujetos al mirarlos (sinóptico). Esta posición de ser simultáneamente el que mira, y por ello un lugar potencial de la mirada de otro, es uno de los ejes sobre el que parte el concepto de 'otredad'.

\section{La Mirada y la vista de PARAlaje}

En el Seminario 11, impartido en 1964, Jacques Lacan constantemente se refiere a la pintura LoS embajadores, de Hans Holbein. Los hombres que aparecen en ella, sus ropas y los objetos están llenos de detalle, pero roba la atención por mucho una especie de mancha extraña en primer plano. Resulta ser un cráneo, dibujado de tal modo que sólo es visible cuando vemos la pintura desde cierto ángulo: la obra nos indica la posición que debemos tener para verla completa, y en ese sentido, nos incluye en sí misma. Además, al asumir esa posición y ver el cráneo, dejamos de percibir el resto del cuadro: el lugar desde donde se mira tuerce la realidad de modo que se vuelve incomprensible una vez que se asume dicha posición.

Lacan (1987: 80) utiliza esta pintura para señalar que hay una mirada que nos preexiste. Yo puedo ver hacia un lugar, pero también puedo ser mirado desde todos lados: hay en el mundo algo que ya me está viendo (el orden Simbólico), y por el que, antes de ver, yo ya estoy "dado-aver" (1987: 82).
¿Cómo podemos entender este "me veo verme" que menciona Lacan (1987: 88) y que es el modo en que entendemos nuestra inclusión en la mirada? La película Film (Schneider, 1965), protagonizada por Buster Keaton y escrita por Samuel Beckett, presenta una muy interesante solución. Un personaje con cataratas corre hacia su departamento. La cámara va alternándose entre una toma 'objetiva' que lo enfoca y el punto de vista del personaje. Al llegar a su austero cuarto, tapa la ventana, saca a los animales, pone una tela sobre la pecera, retira la pintura de la pared, rompe las fotografías: intenta con desesperación controlar la mirada de la Otredad que lo acosa. Cuando cree haber terminado y se sienta en la mecedora, la cámara 'objetiva' se pone frente a él y el personaje grita: en un contraplano vemos que la cámara es el punto de vista de un doble suyo (se concreta así la transformación de la toma objetiva a subjetiva), por lo que termina tapándose los ojos.

La lección de la película es que en la percepción no sólo están las cosas que percibo, también me puedo ver a mí mismo percibiendo: toda percepción incluye lo que se percibe y la condición de percepción misma que enmarca lo percibido (en lacaniano, todo enunciado incluye sus propias condiciones de enunciación).

En el mismo Seminario, Lacan afirma: "El cuadro, es cierto, está en mi ojo. Pero yo estoy en el cuadro" (1987: 103). Es así como puedo hallarme en el objeto que me devuelve la mirada: no sólo me construyo subjetivamente cuando me percato de que soy objeto de la mirada de alguien más (como lo entiende Sartre) ${ }^{8}$ además

8 Hasta ese Seminario, Lacan planteaba el tema de la Mirada en el sentido en que lo usa Sartre, a partir de El ser y la nada (1943): me constituyo como sujeto en el momento en que entiendo que puedo ser un objeto para alguien, así que yo nazco como sujeto gracias al Otro-Prójimo que me mira. Para poder entender el funcionamiento de la Otredad como el orden Simbólico que se halla 'al interior' de cada sujeto, es necesario que la Mirada pueda encontrarse en un objeto y que el sujeto se inserte en ella. Es ahí donde Lacan se despega del humanismo de Sartre. 
hay un Otro que me está mirando todo el tiempo y en el que yo me enmarco (el orden Simbólico que, finalmente, es el propio lenguaje). El matema lacaniano para esto es \$(A): el Sujeto está barrado en tanto viene escindido al interior por el significante, por el gran Otro (Autre) que lo sanciona, el Otro que ya lo estaba siempre mirando y que habita dentro de él.

Todo esto supone que al sujeto le va bien su nombre, pues es tal en tanto está 'sujetado' a algo. Siguiendo la dicotomía clásica, iqué viene a ser el objeto? Algo que ‘objeta' al sujeto, se interpone en su camino, lo confronta, lo perturba, lo acosa. Para Žižek, esta objeción a mi subjetividad por parte del objeto es posible a partir de una 'vista de paralaje', la cual define como "the apparent displacement of an object (the shift of its position against a background), caused by a change in observational position that provides a new line of sight" (2006: 17). ${ }^{9}$

Lo anterior significa que la objeción que supone un objeto no es una simple relación de resistencia o antagonismo hacia mí, por el contrario, nace con mi cambio de posición respecto a él. Esta posición diferente supone la más básica diferencia, la 'diferencia mínima', que no se da entre un objeto y otro, sino 'al interior' del objeto, antagonismo que sólo se puede ver gracias a que cambio mi posición de mirada, a que 'miro torcido' al objeto. Mi subjetividad nace, justamente, en esta torcedura.

Para entender este punto, el ejemplo usado por el propio Žižek (2006: 25) es muy útil: en su Antropología estructural, Lévi-Strauss señala que, al pedirle a dos grupos con diferente jerarquía en la escala social de la tribu Winnebago que dibujaran un mapa de su aldea, obtuvo dos resultados distintos. Uno de ellos consistía en dos círculos concéntricos alrededor del templo

9 "el aparente desplazamiento de un objeto (el cambio de su posición respecto al fondo), causado por un cambio en la posición de observación que provee un nuevo punto de vista" (la traducción es mía). principal, y el otro era una aldea claramente dividida entre el grupo superior e inferior. Una lectura ingenua ve en esto un problema de falta de herramientas precisas: podemos simplemente hacer un mapa 'objetivo' de la aldea y así saber cuál grupo 'tiene la razón'. El inconveniente de esta idea es que, aunque trazáramos un dibujo más acorde con la realidad económica de la colocación de las casas, pasaríamos por alto el hecho de que la división social atraviesa el imaginario de distribución espacial con el que los habitantes ven su hogar.

Esta es una vista de paralaje: la diferencia se encuentra al interior del objeto mismo a partir de un cambio en el punto de percepción. La vista de paralaje no nos permite ver las cosas 'objetivamente', pero logramos aprehender dimensiones distintas de las mismas a partir de un cambio en la posición de la mirada gracias a la intrusión de algo que perturba el orden Simbólico del mundo. El nombre lacaniano para esta dimensión de perturbación es lo Real.

Lo Real es la mancha que revela la debilidad y arbitrariedad del entramado Simbólico. Gracias a esta vista de paralaje y a la intrusión de lo Real, el objeto objeta mi subjetividad, y por lo tanto me desancla, rompe mi sujeción. Para comprender la importancia de este concepto en el desarrollo del sujeto, se perfila la necesidad de reflexionar sobre la relación de éste con la ideología.

\section{EL SUJETO IDEOLÓGICO}

En el clásico de 1969 de Althusser, Ideología y aparatos ideológicos del Estado, posiblemente el más influyente texto sobre el tema, se señala con claridad la función del sujeto:

la categoría de sujeto es constitutiva de toda ideología sólo en tanto toda ideología tiene por función la 'constitución' de los individuos concretos en sujetos. El funcionamiento de toda ideología existe en ese juego de doble 
constitución, ya que la ideología no es nada más que su funcionamiento en las formas materiales de la existencia de ese funcionamiento (2014: 60).

Para Althusser, el individuo se vuelve sujeto mediante la 'interpelación', proceso por el cual se reconoce como sujeto ideológico, es decir, se reconoce en un llamado (en el ejemplo de Althusser, un policía grita: “iEh, usted, oiga!”). Para el francés, los individuos son "siempre ya sujetos" (2014: 62), así que la ideología funciona en dos vías retroactivas: 1) soy llamado, pero para ser llamado, 2) yo tengo que reconocerme en el llamado. Es aquí donde se retoma lo fundamental del gran Otro de Lacan, como una agencia que 'siempre ya' nos está mirando: en términos althusserianos, el gran Otro de Lacan que preexiste es la ideología para la que los individuos son 'siempre ya sujetos'.

Esta preexistencia de los individuos como sujetos antes de ser interpelados (y la paradoja de que, al ser interpelados, se convierten en sujetos) le es sumamente útil a la ideología para mantenerse oculta y presentarse como un estado 'natural' de las cosas. Como señala Althusser, ninguna ideología se presenta a sí misma como ideológica: el individuo que cree ver las cosas fuera de ella es el más ideologizado que existe (2014: 65).

Hoy más que nunca vemos esto en el caso del conocimiento científico 'objetivo'; por ejemplo, en la lógica capitalista de la modificación genética (con el fin de retardar el envejecimiento o elegir el color de ojos de un bebé). Se cree que hay preguntas que la ciencia puede plantearse 'objetivamente' (¿qué pasa si movemos estos cromosomas de lugar o modificamos el ADN de este modo?), y que es la ideología la que pervierte los resultados para beneficio de alguien. Pero la ideología actúa, siguiendo la idea althusseriana de que 'siempre ya somos sujetos ideológicos' y la lógica lacaniana de que 'siempre nos están mirando ya', desde el propio proceso de la pregunta 'objetiva' que plantea la ciencia, enmarcada en un lado oscuro donde se revela la posición de enunciación del sujeto. ${ }^{10}$ Es aquí donde vale la pena invertir la idea coloquial y desinformada de que 'alguien tiene una ideología': como ya preexistimos en ella, es la ideología la que nos tiene a nosotros.

Ahora, este intento de la ideología por hacer pasar como 'naturales' procesos que tienen sentido justo por estar dentro de ella se da por la necesidad de ocultar el fundamento obsceno del entramado ideológico. Precisamente, así es como Žižek, en 1997, define la ideología: "es el campo simbólico en el que un relleno dado ocupa el lugar de una imposibilidad estructural determinada y en el que, al mismo tiempo, se reniega de esa imposibilidad" (2011: 88).

La salida ingenua ante el problema planteado es que debemos 'quitarnos' el velo ideológico para ver las cosas 'como realmente son'. El inconveniente de esta opción es que no logra reconocer que, en el entramado simbólico, las cosas ‘son' lo que aparentan. La crítica estándar pide que busquemos la realidad más allá de las apariencias, pero el engaño ideológico es, justamente, creer que hay algo detrás de ellas, no ver el rol simbólico que juegan en la constitución del mundo.

Regresemos a Lacan. En el Seminario 11 (1987: 110) nos recuerda la historia de Zeuxis y Parrasio, dos pintores griegos que hicieron un concurso para saber cuál era el mejor de ellos. Se citaron cada uno con un cuadro, ambos ocultos con una cortina. Zeuxis corrió la suya y mostró unas uvas tan realistas y perfectas que los pájaros bajaron a picotearlas. Confiado de su éxito, le pidió a Parrasio que hiciera lo mismo, pero se topó con una gran sorpresa: su obra era la pintura de una cortina. Lo que se toma de esta

10 Es aquí donde nace el Discurso Universitario, estudiado en 1975 por Lacan en el Seminario 17 (1992): la verdad que impulsa al agente del Conocimiento es el Significante Maestro, el agente del Discurso del Amo. 
anécdota es que la apariencia de las cosas no oculta una 'verdad profunda', sino que debemos reconocer 'la verdad de la apariencia misma'. Con esto podemos empezar a minar el edificio ideológico y hallar la 'imposibilidad estructural' sobre la que se asienta, es decir, el núcleo de lo Real al interior del edificio Simbólico.

En su concepción más básica, lo Real es aquello que no se puede simbolizar. Lo Simbólico supone que el arreglo de sentido a partir del signo, siempre se hace produciendo un corte en lo Real. Esto no significa que el edificio Simbólico se asiente 'sobre' lo Real o que lo 'oculte', mucho menos que lo 'sustituya'; sino que 'en su interior habita lo Real'.

La imposibilidad estructural de la que habla Žižek es ese Real que amenaza con demostrar la arbitrariedad y debilidad de la ideología. Esta última constituye el intento por tapar el hueco que abre lo Real en lo Simbólico, tentativa que nunca será suficiente: siempre se cuela lo Real, hay una falta en el registro del Otro, de lo Simbólico, que no se puede sanar.

En matemas lacanianos, esa falta en el Otro se representa como $\mathrm{S}(\AA)$ : cuando el Otro está tachado, se obtiene el sujeto. Esto supone una inversión del sujeto interpelado althusseriano: para el psicoanálisis, el sujeto no es aquél que cumple la interpelación ideológica cual máquina, sino que surge en los tropiezos del lenguaje, las manías, tics y sueños, es decir, en las manifestaciones del inconsciente, de la falla del Otro (en el glitch de la Matrix, para citar la famosa película).

Gracias a la mirada de paralaje 'del' sujeto, que halla la diferencia 'en' el interior del objeto, se revela la imposibilidad estructural sobre la que se construyen el objeto y la ideología. El sujeto no es el que cumple con el llamado ideológico (perspectiva de Althusser), por el contrario, surge ahí donde falla el orden Simbólico y no llega el llamado ideológico. Si bien el sujeto del lenguaje está castrado (\$), esto supone el nacimiento de un residuo que se resiste a la simbolización.
Siguiendo esta idea, es importante insistir en que lo Real no se reduce entonces a lo que no puede entrar al edificio Simbólico, porque esto significaría que este último tiene una construcción ajena a lo Real: más bien, todo orden Simbólico se construye 'alrededor' de esa mancha/falla de lo Real. Es en las grietas del edificio Simbólico donde se manifiesta y se encuentra la dinamita de su propia destrucción.

Sobre lo anterior, en 1999 Žižek amplió la reflexión sobre la imposibilidad estructural al interior de la ideología (2008a: 303): si bien el funcionamiento de un edificio ideológico genera sus propias condiciones de resistencia, lo importante para desestabilizarlo es continuar al final con su propia lógica. Podríamos creer que ofrecer resistencia a la ideología desde las condiciones de enunciación de la misma es seguirle el juego y no hacer ningún daño; la ironía reside en que un modo de destruirla es permitir que continúe su camino, siempre y cuando hagamos más grande la brecha inherente al interior de su propio edificio.

Nuevamente, el cine provee un gran ejemplo de esto. En la película Borat: Cultural Learnings of America for Make Benefit Glorious Nation of Kazakhstan (Charles, 2006), un misógino, homófobo, antisemita y sumamente despistado presentador de noticias de Kazajistán, llamado Borat, viaja a Estados Unidos para conocer su cultura. Sus desafortunados encuentros con feministas, políticos, vaqueros y la alta sociedad sureña le causan muchos (divertidos) problemas.

Lejos de ser sólo un 'extraño', Borat es un personaje que explota la grieta al interior del edificio ideológico del Occidente 'civilizado', pues al oponerle resistencia con su expresión absurda de otredad, logra que se caiga. La escena de la cena formal, en la que un grupo de parejas trata de enseñarle modales en la mesa y etiqueta formal (mientras lanzan comentarios como que pronto se 'adaptará' a ese estilo de vida) constituye, en ese sentido, la más importante de todo el filme: 
la ideología trata de domesticar al salvaje/otro/ Borat, enseñándole cómo usar el inodoro y los cubiertos, pero él no cabe por la puerta del edificio ideológico, se le resiste (se lava la cara con el agua del inodoro y pregunta si puede defecar en el lavabo).

El punto donde la ideología termina desechando al personaje, rindiéndose ante la imposibilidad de dar cuenta de su otredad, es cuando llega a escena una prostituta, negra, obesa, con nulo sentido de una etiqueta y moda que sea cómoda para el grupo que está cenando, es decir, cuando el capitalismo multicultural que 'acepta la diferencia' se enfrenta a su propio residuo. Al arribar esta paria del sistema nos damos cuenta de la falla inherente a la civilización 'tolerante y multicultural': la ideología no soporta toparse con su residuo, con su imposibilidad estructural, lo Real que habita en su interior.

\section{Del enunciado subjetivo a la enunciación objetiva}

Ante el enfrentamiento con lo Real, la ideología tiene la opción de intentar domesticarlo con sus herramientas simbólicas (tentativa que eventualmente demostrará su imposibilidad de éxito), o deshacer el edificio totalmente. Borat y la prostituta intentan entrar al entramado Simbólico del Occidente civilizado, blanco, capitalista y cristiano, pero no caben por la puerta. Las herramientas de la ideología no alcanzan para meterlos, así que sólo queda romper la pared (rehacer el entramado Simbólico con esa intrusión de lo Real), o expulsarlos totalmente (lo que termina pasando en el filme) con tal de salvar al Otro ideológico.

Es por ello que, en un primer momento, resultan tan traumáticas para los entramados ideológicos luchas como la del matrimonio homosexual. Su reconocimiento no sólo supone un arreglo del signo (inscribir esa unión en registros civiles, celebrar bodas entre dos hombres o dos mujeres, etcétera), sino la desestabilización de la institución misma del matrimonio. La solución 'mediadora' consiste en crear figuras legales (como sociedades de convivencia) que tuercen un poco el edificio, pero terminan salvando la institución heteronormativa (en ese sentido, dichas soluciones son todo menos progresistas). Lo verdaderamente radical es poner en duda el entramado completo de la institución, otorgando exactamente los mismos derechos, sin ese cómodo avance tibio: en el camino, muy posiblemente lo que entendemos por matrimonio cambiará. Lo mismo sucede con el aborto y la institución de vida humana, o el feminismo y la institución de diferencia sexual.

El sujeto ideológico (Althusser señala que eso es una tautología) usualmente se siente interpelado a actuar en esta crítica ideológica, a tomarse las cosas 'personalmente'. Por ello abundan comentarios como: "no todos los hombres acosan mujeres', o 'no todos los sacerdotes violan niños'. El problema de estas afirmaciones es que no alcanzan a distinguir entre la verdad del enunciado y la posición de enunciación. Es cierto, en términos del enunciado, que no 'todos' los hombres acosan mujeres y no 'todos' los sacerdotes violan niños; pero el punto con la denuncia sobre el acoso callejero y el encubrimiento de la pederastia por parte de la Iglesia no es señalar esto al nivel del individuo (del enunciado), sino al nivel del sistema (de la enunciación). Si bien no todos los hombres son acosadores en la calle, los modelos de masculinidad promueven una posición de sometimiento de las mujeres; y aunque no todos los sacerdotes violan niños, este delito se vuelve mucho más perverso pues la estructura hermética y estrictamente jerárquica de la Iglesia (y la posición de poder moral y confianza que tienen en una comunidad específica) permite que estos casos se oculten y continúen por años sin que los criminales enfrenten justicia alguna.

La lucha de lo 'políticamente correcto' también encuentra este impasse, la brecha entre el enunciado y la enunciación. Ejemplo de esto son 
las actitudes body positive: aceptarse a sí mismo y a los demás como son (particularmente, a las personas con sobrepeso u obesidad). Uno puede ver claramente que suponen una resistencia a los estándares de belleza que promueve la industria de la moda, el maquillaje, la comida y la pornografía, modelos que no corresponden con la diversidad física humana y que han causado tanto daño en el desarrollo emocional de niños, adolescentes y adultos. Las personas que piden la aceptación de su cuerpo denuncian haber sido acosadas por estos estándares no realistas, y ser discriminadas en espacios públicos. Sin embargo, uno no puede quitar el dedo del renglón y señalar que es cierto que el sobrepeso acarrea mucha más probabilidad de sufrir problemas de salud de todo tipo, y que el estilo de vida de las personas que lo padecen muy probablemente (en áreas urbanas) está basado en una explotación de recursos naturales del capitalismo de la comida rápida. La cuestión aquí, sin embargo, no es señalar al individuo y despreciarlo: por supuesto, se debe tolerar, respetar y no discriminar por la apariencia física, sea ésta elegida o no, pero esto no puede suponer no tratar de seguir (y promover) un estilo de vida saludable, acorde con los ya muy escasos recursos naturales de este planeta y la realidad biológica del cuerpo humano.

En función de este cuestionamiento del edificio ideológico tiene sentido discutir la idea ingenua de ser tolerantes ante todo, menos ante la intolerancia. Se supone que debemos convivir con todas las ideologías y cosmovisiones siempre y cuando éstas no recurran a la violencia en contra de las demás. En ese sentido, el fascismo es intolerable porque agrede violentamente a las diferentes razas y religiones. El terrorismo islámico no se puede soportar por sus atroces actos. El problema de esta actitud es que se queda enfrascada en la 'violencia subjetiva' sin ver la 'violencia objetiva', distinción establecida por Žižek (2008b): la primera es la que un sujeto ejerce contra otro (el fascista que golpea en la manifestación, el terrorista que le corta el cuello a un periodista), la segunda es la violencia estructural que crea las condiciones que se manifiestan subjetivamente.

La lucha por control económico de los grupos que se disfrazan de nazis o de fundamentalistas islámicos no los hace nazis/fundamentalistas hipócritas, sino que es 'a través' del discurso nazi/fundamentalista que se cumplen los objetivos de alcanzar el poder económico. Es precisamente esta dimensión la que no se alcanza a ver a menos que uno 'tuerza su mirada' y pueda hallar ahí el impasse de la democracia liberal.

\section{DEL CAPITALISMO FRIENDLY A LA LUCHA UNIVERSAL}

Gracias a este cambio en la perspectiva (vista de paralaje), se nos permite ver el mayor trauma para la democracia liberal contemporánea. El capitalismo de hoy se ha apropiado con facilidad de diversas luchas que, décadas atrás, fueron iniciadas por grupos de izquierda (por la ecología, los derechos sexuales, los problemas raciales, las minorías étnicas, etcétera). Todas estas batallas pueden tener éxito en sus demandas siempre y cuando cumplan el requisito más vital del neoliberalismo: la acumulación de más y más capital en el más y más (supuestamente) libre mercado.

Podemos ver esto en los desfiles del orgullo gay, convertidos en una industria donde se anuncian marcas y negocios, disfrazada de una lucha por la igualdad de derechos; en las campañas contra el plástico de un solo uso (como los popotes), que son un pretexto para seguir creando productos que cubren una supuesta necesidad, pero que causan otros daños ambientales (popotes de metal o tapas para café con huecos a los lados); ${ }^{11} \mathrm{y}$ en el periodismo, que vende historias de desarrollo personal y superación de

11 A menos de que estemos tomando mate o tengamos un problema específico en la boca, irealmente necesitamos un popote para beber? 
obstáculos (niños que caminan kilómetros para llegar a la escuela o madres solteras que tienen tres trabajos para pagar la comida), que ocultan la violencia sistémica del olvido de las zonas rurales y el capitalismo que explota a los trabajadores con sueldos de miseria.

La imposibilidad estructural sobre la que se asienta el edificio ideológico del mundo tolerante, multicultural, que reconoce la lucha particular, se nota también en la mercadotecnia 'social' que promueven las trasnacionales y adoptan las pequeñas empresas, con su 'apertura' a las diferencias. Así, nos topamos con frecuencia negocios que dicen ser pet friendly, gay friendly, eco friendly, espacios seguros, etcétera, pero que sobre todo (y esto es lo que no dicen) son capitalist friendly: es el sistema capitalista el que se ha apropiado de esas luchas particulares para seguir funcionando sin oposición alguna.

Esta paradoja es lo que nuestras democracias liberales, preocupadas por las luchas particulares, no alcanzan a ver. La lucha particular supone una pelea por el reconocimiento de la horizontalidad, la creación de condiciones de igualdad donde cada quien (heterosexuales, homosexuales, transexuales, asexuales; blancos, negros, morenos; indígenas, inmigrantes, cosmopolitas) pueda desarrollar todo su potencial. Siempre apuesta por la mediación, y es particular no sólo porque defiende los intereses de uno u otro grupo, sino porque cambia sus lógicas a cada paso. Asimismo, se sostiene en el libre mercado de las elecciones democráticas, de modo que cada quien tenga su turno de ocupar el poder.

Existe, sin embargo, una traba muy grande en esta lógica: la lucha de clases, una lucha universal, pues no se detiene en la resolución de un conflicto que puede mediarse y resolverse. La lucha de clases sólo se soluciona con el aniquilamiento del otro, palabras que en nuestras sociedades liberales tienen connotaciones muy negativas, pues están acostumbradas a 'trabajar más allá de las diferencias'.
Como señala Žižek (2006: 362), la lucha particular trata de traducir el antagonismo (entre sexos, razas, etnias) en diferencia, de modo que cada particular pueda desarrollarse sin ser sometido por el otro; pero la lucha de clases, al ser universal, debe elevar ese antagonismo al máximo: no trata de resolver las diferencias y hallar mediaciones, sino que intenta aniquilar al enemigo. No hay modo en que la burguesía y el proletariado convivan pacíficamente, alcanzando cada uno su potencial: la lucha universal es la batalla por ganar en todos los terrenos al contrario, sin importar el particular desde el que se enuncie.

En la democracia liberal se puede aceptar el matrimonio homosexual, el aborto, la legalización de las drogas, la igualdad racial y muchas otras luchas que algunos creen que, por adscribirse a ellas, son 'progresistas' o 'de izquierda'. Lo inaceptable es la batalla por cambiar la lógica de acumulación del capital, el sistema económico de raíz. Por ello, regresando a Mathiesen, podemos disfrutar la mayor de las diversidades, pero seguir atrapados en la máxima desigualdad: es posible imaginar - y ver en casos actuales - contenidos que promueven y abrazan la diversidad étnica, sexual, racial, etcétera; pero al advertir la distribución inequitativa de la ganancia y la explotación económica, recordamos que la diversidad no debe ser el fin, sino un medio.

Un ejemplo donde se ve este problema es la serie Easy (Swanberg, 2016), producida por Netflix. Durante su primera temporada, mostró una inclinación por historias eróticas y románticas, ambientadas en una urbe cosmopolita, entre personajes de diferentes edades, orígenes e identidades sexuales. Este ingrediente no falta en el primer capítulo de la segunda temporada, donde un grupo de habitantes de un vecindario de clase alta (matrimonios interraciales, con empleos sofisticados, hombres de cabello largo, etcétera) empieza una ronda de vigilancia tras notar los robos de su correspondencia y paquetes. La 
tensión, supuestamente cómica, escala al punto de que llaman a la policía porque dos jóvenes 'sospechosos' están estacionados en la calle. Al final, logran atrapar al ladrón, pero lejos de que el capítulo plantee una lección a los vecinos sobre su racismo y prejuicios, todo queda en un malentendido que nunca supone una reflexión personal sobre las condiciones de su clase y privilegios. Tanto se mantiene intacto el statu quo que ni siquiera se ve el rostro del ladrón, mucho menos se conocen sus motivaciones: sencillamente no importa él, sino su rol como perturbador de la paz de vecinos que respetan las diferencias étnicas y tienen un gran sentido de comunidad multicultural, mientras disfrutan sus mansiones, ropa de diseñador y autos de lujo. Al final regresan a su normalidad.

La izquierda ya no puede seguir definiéndose, como lo hacía en décadas pasadas, por una búsqueda de mayor representación de las minorías. En la democracia liberal y participativa de hoy, donde se dice que se puede 'trabajar más allá de las diferencias', y por una 'agenda común' - modo en que se justifican alianzas de partidos supuestamente distantes en el espectro político- resulta que, en efecto, desaparecen los desacuerdos.

Es aquí donde otro francés resulta útil. Jacques Ranciére (2015: 44-46) ofrece una distinción entre 'policía' y 'política': la primera es el campo de la unificación, de la 'constitución simbólica de lo social'; mientras que la política constituye la intervención en ese campo, el disenso que demuestra la grieta en él. En ese sentido, Ranciére es muy lacaniano: la política es la grieta Real dentro de todo campo de constitución Simbólica.

Al ofuscar el campo de batalla político-ideológico con alianzas y agendas comunes en las democracias liberales, la política deja de definirse por el antagonismo y el conflicto a partir de un ideal, y empieza a ser un diálogo que permite, justamente, una única agenda, la más importante: mantener el estado actual de la economía. No importa la democracia del particular si ésta no puede traducirse en universal. A esto se refería Lenin en 1918 cuando, en el debate sobre Kautsky, señaló: "Es lógico que un liberal hable de 'democracia' en términos generales. Un marxista no se olvidará nunca de preguntar: '¿Para qué clase?'” (2007: 15).

Por ello, es importante regresar a la noción de economía política. No debemos seguir creyendo que hay 'muchas' izquierdas, sino reconocer sólo una verdadera: la izquierda económica, que busca cambiar, fundamentalmente, las relaciones en este ámbito.

Esto no supone, en ningún momento, ignorar o despreciar las luchas por mejores condiciones para las mujeres, o para eliminar los prejuicios raciales o étnicos. Lo que implica es que estas batallas pueden ganarse y a la vez contribuir a la lucha universal, ésa es la bandera que podemos promover. Al término de la Segunda Guerra Mundial, los soldados regresaron a sus hogares y se toparon un mundo muy cambiado, donde muchas mujeres comenzaron a trabajar por primera vez, y con ello, a tener su propio patrimonio económico, lo cual puso la balanza un poco más justa. Unos años después, comenzó en Estados Unidos la llamada segunda ola del feminismo. ¿Es demasiado arriesgado pensar que un leve movimiento para mitigar la desigualdad económica empezó a generar una mayor conciencia sobre otras desigualdades, es decir, que comenzar a resolver la desigualdad económica fue el paso para intentar solucionar otras injusticias?

La noción de paralaje, de mirar torcido, tiene sentido aquí porque la constitución ideológica del sujeto en el capitalismo parte de ocultar el antagonismo fundamental en lo social, que no es el sexual, de género, raza o etnia, sino de clase. Esto es lo que provee el psicoanálisis que no alcanza a discernir Althusser; como bien afirma Mladen Dolar (1993), la interpelación althusseriana crea un sujeto constituido y completo, 
mientras que Lacan sí alcanza a ver el residuo que nace con la constitución del sujeto, el núcleo de lo Real que insiste y perturba su constitución Simbólica.

Como señala Alenka Zupančič (2017: 139), y que unimos con el ejemplo del mapa de las casas dado por Žižek, la lucha de clases no supone una conclusión del entramado simbólico, no nace a partir de ver las cosas 'objetivamente' (cosa que, nunca sobra la insistencia, no se puede hacer): es el concepto que fundamenta una comprensión del mundo, gracias a él podemos entenderlo, constituye el punto de armado ideológico que nos permite ver las cosas (el point de capiton lacaniano).

Por ello, debemos deshacernos de la idea de que dentro de nosotros habita la 'esencia' de nuestro ser, un 'genuino' núcleo individual que creemos tener, y darnos cuenta de que somos una especie de marioneta de la Otredad - $\$(\mathrm{~A})$ como la novia de Truman, que le habla a su pareja con el guion de un comercial de televisión. ¿No nos hemos comportado así en muchas ocasiones en nuestra interacción con los demás, siendo hablados por un Otro que habita en nuestro interior, revelando cómo nos encanta seguir sedados en el capitalismo y consumo más brutal? ${ }^{12}$

Así que, aunque parezca paradójico en una primera aproximación, lejos de 'quitarnos' los lentes ideológicos deberíamos asumir que siempre los tenemos puestos, y denunciar que esos modos 'objetivos' de ver las cosas son modos

12 Un ejemplo de esto lo constituyó el debate en México sobre la potencial cancelación del Nuevo Aeropuerto Internacional de la Ciudad de México. El espectro de 'discusión' en los medios masivos de comunicación anclados a la lógica del neoliberalismo tenía un punto de partida definido (el aeropuerto debe construirse), estableciendo un camino trazado desde ahí. Para ellos, lo grave no eran los sospechosos contratos, precios inflados o el irreversible daño ambiental (incluso las intervenciones de expertos en esta materia fueron directa y explícitamente censuradas en televisión), sino la lógica de 'terminar el aeropuerto y general empleos' contra 'detenerlo, perder mucho dinero y asustar a la inversión privada extranjera'. Es aquí, de nuevo, donde la pregunta 'objetiva' al respecto de un tema ya es parte del problema que intenta resolver, pues predirige el sentido de la respuesta. ideológicos con los que se ha torcido la realidad: es necesario señalar la falla en el entramado ideológico y así enunciar nuestra subjetividad -S $(A)$ -

Irónicamente, puede resultar útil la lógica multicultural de que 'todas las luchas son válidas', 'se puede trabajar más allá de las diferencias', 'se debe tolerar todo menos la intolerancia', 'es posible convivir, aunque se esté en desacuerdo'. Podemos defender esas ideas liberales siempre y cuando haya un compromiso con una bandera en la que las diferencias de todo tipo (los diversos particulares de banderas de todos los colores y combinaciones) se aglutinen, pues los sujetos se reconocen como interpelados por una única lucha.

Se debe así enunciar una universalidad desde una posición particular: una universalidad capaz de decirse siempre, no importa la particularidad desde la que se esté. No anulará la particularidad sexual, racial, étnica o de otro tipo, sino que desde ese campo impulsará la lucha universal. Esta bandera es la de la lucha de clases, el núcleo de lo Real sobre el que se sostiene el entramado ideológico de hoy. Con la vista de paralaje que esta idea nos provee, la torcedura que nos produce al ver la sociedad, se puede constituir un sujeto que sea un agente de verdadero cambio, uno que logre encontrar, ante los problemas particulares, una salida 'común'. 


\section{REFERENCIAS}

Althusser, Louis (2014), Ideología y aparatos ideológicos del Estado. Práctica teórica y lucha ideológica, México, Grupo Editorial Tomo.

Charles, Larry (dir.) (2006), Borat: Cultural Learmings of America for Make Benefit Glorious Nation of Kazakhstan, cinta cinematográfica, Estados Unidos, 20th Century Fox.

Dolar, Mladen (1993), "Beyond Interpellation”, Qui Parle, vol. 6, núm. 2, pp. 75-96.

Foucault, Michel (2003), Vigilar y castigar. Nacimiento de la prisión, Buenos Aires, Siglo XXI Editores.

Lacan, Jacques (1987), Libro 11. Los cuatro conceptos fundamentales del psicoanálisis, Buenos Aires, Paidós.

Lacan, Jacques (1992), Libro 17. El reverso del psicoanálisis, Buenos Aires, Paidós.

Lenin, Vladimir I. (2007), La revolución proletaria y el renegado Kautsky, Madrid, Fundación Federico Engels.

Lyon, David (2005), "9/11, Synopticon, and Scopophilia: Watching and Being Watched", en Kevin Haggerty y Richard Ericson (eds.), The New Politics of Surveillance and Visibility, Toronto, University of Toronto Press. pp. 35-54.

Mathiesen, Thomas (1997), "The viewer society. Michel Foucault's 'Panopticon' revisited", Theoretical Criminology, vol. 1, núm. 2, pp. 215-234.

Rancière, Jacques (2015), Dissensus. On Politics and Aesthetics, Londres Bloomsbury.

Schneider, Alan (dir.) (1965), Film, cinta cinematográfica, Estados Unidos. Evergreen.

Swanberg, Joe (dir.) (2016), Easy, serie de televisión, Estados Unidos, Netflix.

Tibbetts, Carl (dir.) (2014), "White Christmas", capítulo de la serie de television Black Mirror, Reino Unido, Channel 4 / House of Tomorrow.

Žižek, Slavoj (2006), The Parallax View, Massachusetts, MIT Press.

Žižek, Slavoj (2008a), The Ticklish Subject. The Absent Centre of Political Ontology, Londres, Verso.

Žižek, Slavoj (2008b), Violence, Nueva York, Picador.

Žižek, Slavoj (2011), El acoso de las fantasías, Madrid, Akal.

Zupančič, Alenka, (2017), What Is Sex?, Massachusetts, MIT Press.

Sergio José Aguilar Alcalá. Maestro en Comunicación por la Universidad Nacional Autónoma de México (UNAM), México. Actualmente se desempeña como docente en la Universidad Autónoma de Yucatán (UADY), México. Entre sus intereses académicos se encuentran el psicoanálisis, la filosofía y la teoría del cine. Algunas de sus publicaciones recientes son: "Una expresión violenta: mapeando el cine de terror" (El Ojo Que Piensa, Año 9, núm. 16); "Cómo el cine utiliza la ciencia" (Ciencia. Revista de la Academia Mexicana de Ciencias, vol. 69, núm. 2); y "El documental siempre es virtual” (Temas Antropológicos. Revista Científica de Investigaciones Regionales, vol. 39, núm. 2). 